\title{
Climate protection and newly industrialized countries: dilemmas and opportunities in Taiwan
}

\author{
Cheng-Dar Yue ${ }^{\mathrm{a}, *}$, Chih-Hong Sun ${ }^{\mathrm{b}}$ \\ ${ }^{a}$ Institute of Resource and Environment Management, Leader University, No. 188, Sec 5, An-Chung Rd, Tainan, Taiwan, ROC \\ ${ }^{\mathrm{b}}$ Global Change Research Center, National Taiwan University, Taipei, Taiwan, ROC
}

\begin{abstract}
Global climate policy currently is making efforts to mitigate greenhouse gas emissions of industrialized countries through implementation of the Kyoto Protocol. Yet, the development of greenhouse gas emissions in newly industrialized and developing countries is deeply influencing the perspectives of stabilizing the global climate system. This study takes a closer look at the challenges facing Taiwan as an illustrative example to analyze the trends of greenhouse gas emissions, to assess current strategies and their controversies, and to explore strategies for mobilizing national climate policies. Analyzing the aspects of emission caps, carbon taxes, and clean development mechanisms may shed light on the necessity of involving newly industrialized countries and joint reduction into global climate protection schemes. Hopefully, this analysis may provide inspiring insights about the international climate regime and to other newly industrialized and developing countries which can then adopt effective policies for stabilizing the global climate system.
\end{abstract}

(C) 2003 Elsevier Science Ltd. All rights reserved.

Keywords: Climate change; Sustainable development; Energy policy; Integrated assessment

\section{Introduction}

The potential risks of global warming have increasingly given rise to political concerns in the international community. The Kyoto Protocol is an attempt to initiate actions to mitigate greenhouse gas emissions of developed countries.

While the focus of emissions reductions has fallen mainly upon developed countries to date, development in newly industrialized and developing countries is certain to profoundly influence the prospect of stabilizing the global climate system. Identifying the trends of greenhouse gas emissions in these countries and developing effective mitigation strategies for these countries are significant challenges for the immediate global climate policy.

As a rapidly industrializing country, Taiwan has one of the greatest growth rates of greenhouse gas emissions worldwide. Its development path can provide illustrative examples of ways for international climate policy to

\footnotetext{
*Corresponding author. Tel.: +886-6-2553506; fax: +886-62558521.

E-mail address: cdyue@mail.leader.edu.tw (C.-D. Yue).
}

address the challenges of newly industrialized and developing countries to participate in mitigating greenhouse gas emissions in a timely manner.

This study aims to analyze the problems of greenhouse gas emissions in Taiwan, to assess current national strategies and their controversies, and to propose recommendations for national and international climate policies. The methodology used in this study explores the following issues:

- trends of Taiwan's greenhouse gas emissions;

- current national strategies and associated controversies;

- integrated assessment (IA) as a tool to mobilize national climate policy;

- low-carbon strategies; and

- implications for international climate policy.

It is hoped that the experience of Taiwan can provide a meaningful example for the international climate regime and to other newly industrialized and developing countries which can then pursue effective policies for stabilizing the global climate system. 


\section{Trends of Taiwan's greenhouse gas emissions}

Fig. 1, by converting all greenhouse emissions into equivalent $\mathrm{CO}_{2}$ emissions, shows that Taiwan's total greenhouse gas emissions increased by $69 \%$ from 1990 to 2000. $\mathrm{CO}_{2}$ emissions comprised $88 \%$ of Taiwan's contribution to the increase of the greenhouse effect in 2000. The nationwide $\mathrm{CO}_{2}$ emissions in 2000 were 1.8 times the 1990 figure. The share of emissions from the energy sector rose from $76.7 \%$ to $85.8 \%$ during this period (Fig. 2). Energy-related $\mathrm{CO}_{2}$ emissions are the most significant issue in national climate policy, and their importance is continually increasing. Thus, mitigation of energy-related $\mathrm{CO}_{2}$ emissions has a dominant role in this study.

The great rate of growth in $\mathrm{CO}_{2}$ emissions in Taiwan can be attributed to both population and economic growth (Fig. 3), as well as increases in the output of the heavy industries required to construct the facilities and infrastructure for modernizing the economy. Weyant and Yanigisawa (1998) pointed out similar arguments for this interrelationship. Energy demands from expansion of some energy-intensive industries, such as the metal industry, chemical industry, and non-metal

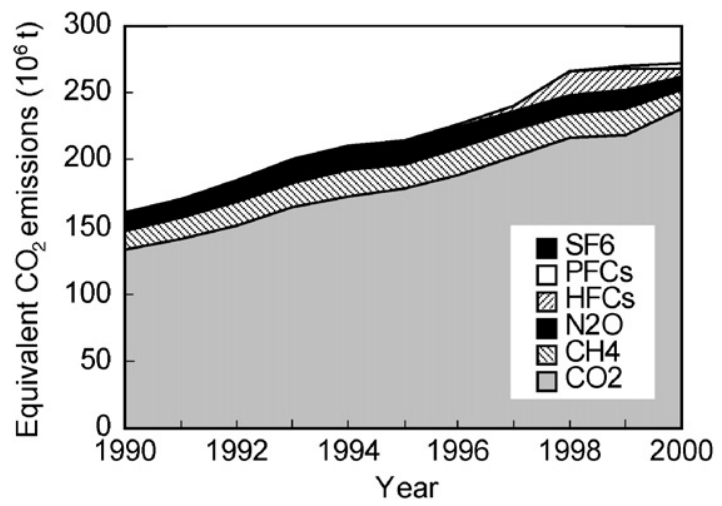

Fig. 1. Greenhouse gas emissions in Taiwan without $\mathrm{CO}_{2}$ from LUCF (Land Use Change and Forestry) (source: ITRI, 2001).

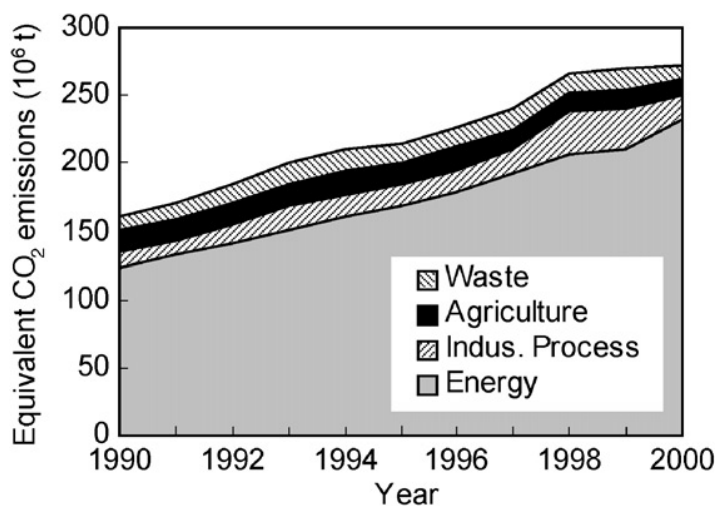

Fig. 2. Greenhouse gas emissions from sectors in Taiwan without $\mathrm{CO}_{2}$ from LUCF (Land Use Change and Forestry) (source: ITRI, 2001).

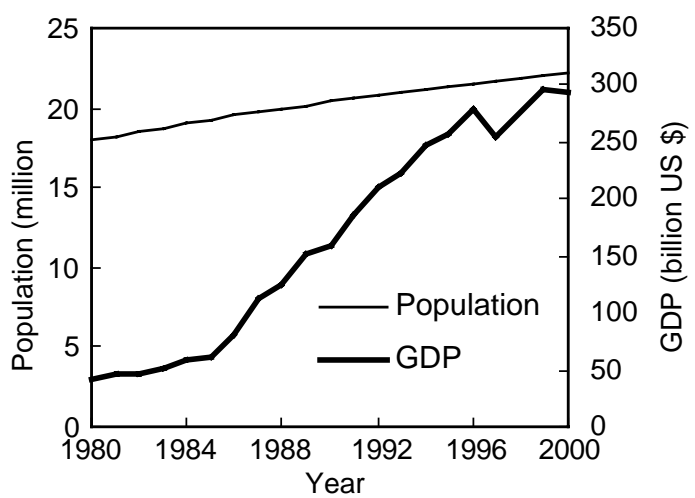

Fig. 3. Population and GDP development in Taiwan (source: DGBAS, 2002)

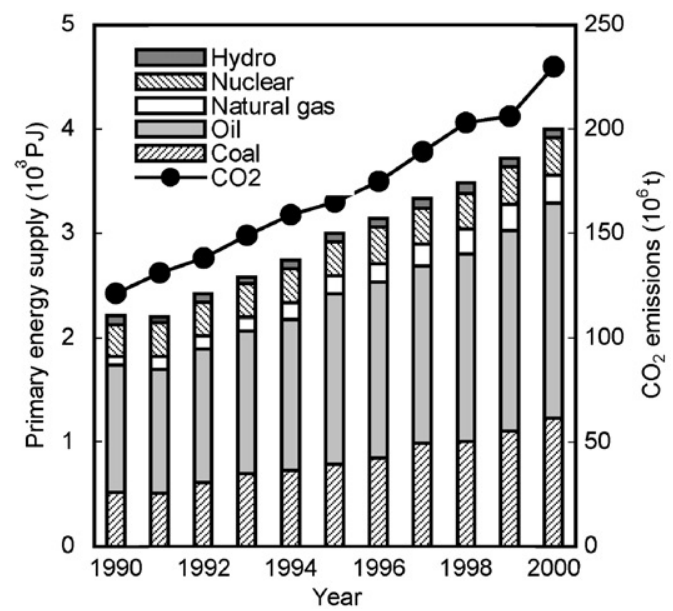

Fig. 4. Primary energy supply by fuel and $\mathrm{CO}_{2}$ emissions induced by fossil fuel combustion in Taiwan (source: EPAROC, 2002).

mineral production, rely mainly on the use of fossil fuels, and thus result in increasing $\mathrm{CO}_{2}$ emissions, as depicted in Fig. 4. Oil comprises over a $50 \%$ share of the entire energy structure and has played a dominant role. Coal is the second-highest consumed energy source. As a whole, fossil fuels comprise over $85 \%$ of the total energy structure, and this creates high levels of $\mathrm{CO}_{2}$ emissions.

Taiwan's per-capita $\mathrm{CO}_{2}$ emissions from fossil fuel combustion increased from 5.5 tons in 1990 to 9.7 tons in 2000. By 1999, Taiwan's per-capita emissions had already exceeded those of Japan and the UK, at a time when many OECD countries were moving toward lower emission levels (Fig. 5). The high growth rate of percapita $\mathrm{CO}_{2}$ emissions of Taiwan indicates the extraordinary challenge in mitigating $\mathrm{CO}_{2}$ emissions facing this country.

Forecasts indicate that future primary energy supplies in Taiwan will continue to grow from 2000 to 2020 by about $62 \%$ (Fig. 6), during a time when the energy structure will not notably change. It should be highlighted that the share of oil is projected to drop from $50 \%$ to $42 \%$; while contrarily, the share of natural gas 


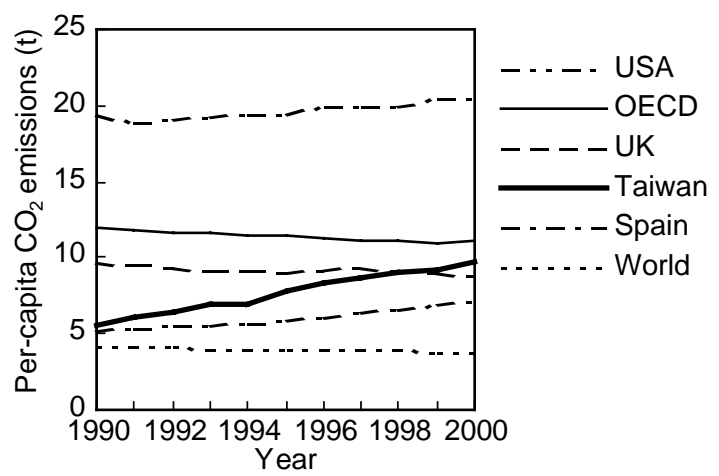

Fig. 5. Comparison of per-capita $\mathrm{CO}_{2}$ emissions from fossil fuel combustion among selected countries (source: IEA, 1999; IEA, 2001; IEA, 2002; UN, 2002; UNFCCC, 2002).

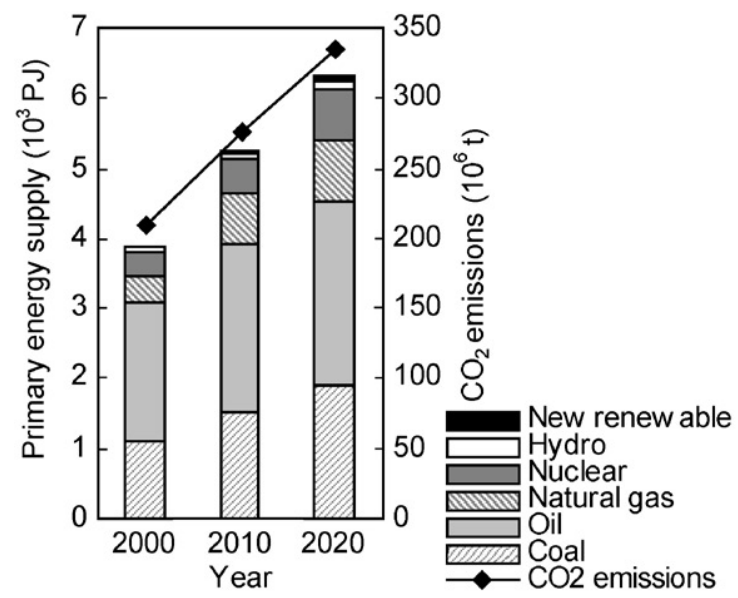

Fig. 6. Predicted primary energy supply by fuel and $\mathrm{CO}_{2}$ emissions in Taiwan (source: ECROC, 1998; Young, 1999).

will expand from $10 \%$ to $14 \%$, nuclear from $8 \%$ to $11 \%$, and new renewable energy forms from $0 \%$ to $1 \%$.

\section{Current national strategies and associated controversies}

\subsection{National strategies}

In addition to population growth and increased economic activity, the lack of an effective climate protection policy is blamed for the expanding consumption of fossil fuels and increased $\mathrm{CO}_{2}$ emissions in Taiwan. Due to diplomatic interference by the mainland Chinese government, Taiwan is excluded from membership in the United Nations and was not allowed to sign the Kyoto Protocol. However, our past experiences with the Montreal Protocol and the Convention on International Trade in Endangered Species of Wild Fauna and Flora were that trade sanctions were imposed on Taiwan due to non-compliance with the Protocol or

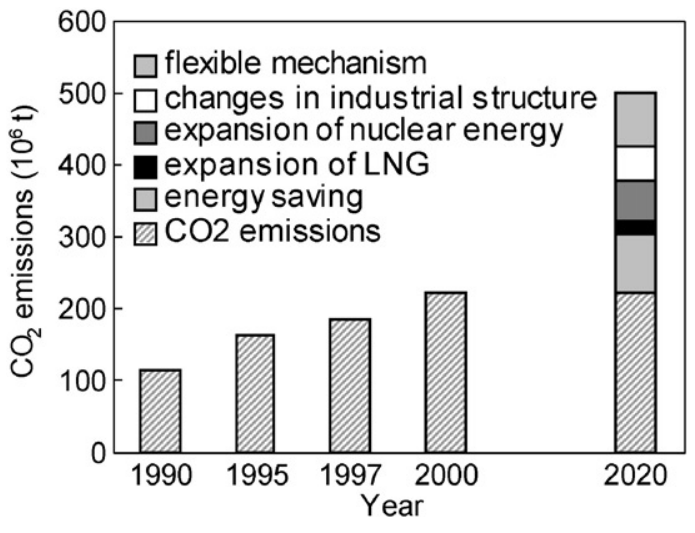

Fig. 7. $\mathrm{CO}_{2}$-reducing measures in Taiwan with their planned $\mathrm{CO}_{2-}$ reduction benefits. The economic growth rate is assumed to have slowed down from $6.8 \%$ in 1997 to $3.5 \%$ by 2020 (source: Chen, 2000; ECROC, 1998)

the Convention, even though Taiwan was not a signature country. This means that Taiwan will have to comply with the relative obligations of the Kyoto Protocol even without signing it.

Despite its diplomatic isolation in the international community, Taiwan's government has announced its intention to share in the common global responsibility for stabilizing the climate system. To date, Taiwan's Environmental Protection Administration (EPA) has participated in the Conference of the Parties of the UNFramework Convention on Climate Change mostly in the status of an NGO. In order to respond to implementation of the Kyoto Protocol, Taiwan's EPA aims to set a target of maintaining Taiwan's $\mathrm{CO}_{2}$ emissions in the year 2020 at the level of that in the year 2000 with 223 million tons as the reference emissions amount according to a resolution of the National Energy Conference held in 1998. This corresponds to 10 tons of $\mathrm{CO}_{2}$ emissions per-capita calculated using the Taiwanese population in the year 2000. This target retains the flexibility of $\pm 10 \%$ of the reference emission amount, and 5 years before and after the reference year of 2020. To achieve this target, the following measures are being considered for implementation between 1997 and 2020 (Fig. 7):

- a drop in the economic growth rate of from $6.8 \%$ to $3.5 \%$;

- a $28 \%$ energy savings rate;

- increased use of liquefied natural gas of from 3.3 to 16 million tons;

- the building of the fourth nuclear power plant, plus expansion of the capacity of the three existing nuclear power plants for a share of an installation capacity of $19-20 \%$ of the total energy supply by the year 2020 ;

- changes in the industrial structure for a reduction of 48 million tons of $\mathrm{CO}_{2}$ emissions; and 
- a reduction of the remaining 74 million tons of $\mathrm{CO}_{2}$ emissions through the flexible mechanism of the Kyoto Protocol.

\subsection{Barriers to implementation}

Along with other newly industrialized countries such as Singapore and the Republic of Korea, Taiwan is not subject to binding limitations of greenhouse gas emissions from the international climate regime. Despite this, Taiwan's EPA is setting forth strategies for mitigating $\mathrm{CO}_{2}$ emissions. Unfortunately, the importance of international environmental benefits has garnered only very limited attention in the national political context, particularly with an ongoing domestic economic recession since 2000. International climate policy does not force Taiwan to reduce its greenhouse gas emissions. As a result of the absence of political pressure at both the international and national levels, legislative fundamentals and implementation mechanisms for climate protection have received a rather low priority in traditionally pro-economic policy considerations.

The shortage of political will and the consequent absence of implementation mechanisms appear to be the key obstacles to Taiwan's climate policy. In this context, there have been few concrete measures set forth to mitigate increased greenhouse gas emissions. EPA strategies remain just a governmental "backup" document for future negotiations with the international community. At the domestic level, it appears that greenhouse gas-producing economic activities will be continued for some years to come. The planning of large steel and petrochemical industries in coastal areas of southwestern Taiwan is a case in point.

\subsection{Controversies over strategies}

The official statement by Taiwan's government as to its participation in the global mitigation of greenhouse gas emissions is to be welcomed. However, some strategies set forth by Taiwan's government have raised other concerns. These include the following.

\subsubsection{Expanding nuclear energy as a substitute for fossil fuels}

Using nuclear energy as a substitute for fossil fuels has brought about some debate in international climate policy. The controversy surrounding nuclear energy results from its incalculable risks and the thorny problem of waste disposal. This consideration can be recognized in the EU's resolution specifically ruling out increased use of nuclear power as an option to mitigate $\mathrm{CO}_{2}$ emissions (ECDGE, 1998).

The current governing party recognizes that nuclear energy is not a sustainable energy alternative for Taiwan, and intends to decommission nuclear power plants ahead of schedule. On this point, two questions must be clarified. First, the expansion of nuclear energy based on climate policy clashes with the policy of decommissioning nuclear power plants ahead of schedule. Second, future energy demands and $\mathrm{CO}_{2}$ emissions based on the decommissioning of nuclear power plants ahead of time need to be considered under coherent energy and environmental policies.

\subsubsection{Absence of perspectives for renewable energy sources}

Renewable energy sources are regarded as one of the key solutions for mitigating global climate change in the future. However, the application of this technology has not been integrated into national future climate and energy policies in Taiwan. In contrast, the flexible mechanism and an expanding nuclear energy imply two gaps which Taiwan's climate policy must fill. Their respective $\mathrm{CO}_{2}$ reductions of 75 and 55 million tons indicate that other alternatives are needed. The possible options in these contexts are addressed below.

\subsubsection{Flexible mechanism}

The flexible mechanisms proposed by Taiwan's EPA are to serve as "backup" measures for reducing national greenhouse gas emissions. The clean development mechanism $(\mathrm{CDM})$ provides the only means within the Kyoto framework of shifting abatement toward nonAnnex I countries. ${ }^{1}$ Article 12, paragraph 9 states that participation under this mechanism may involve private and/or public entities (UNFCCC, 1997). The CDM can provide Annex I countries with incentives of credits for reducing greenhouse gas emissions in non-Annex I countries on the one hand, and for assisting non-Annex I countries to achieve sustainable development on the other. However, since Taiwan is excluded from signing the Kyoto Protocol, only members of Taiwan's private sector that have branches in signatory countries of the Convention have the possibility of participating in CDM projects. Credits of emission reductions from these projects will not accrue to Taiwan. If Taiwan cannot gain credits for emissions reductions, then the $\mathrm{CDM}$ is an invalid measure for reducing greenhouse gas emissions by Taiwan.

\section{IA for mobilizing Taiwan's climate policy}

Insufficient political motivation and promotion mechanisms appear to be the key barriers to an effective climate policy in Taiwan. Finding ways of overcoming

\footnotetext{
${ }^{1}$ Annex I countries: Group of countries included in Annex I to the United Nations Framework Convention on Climate Change, including all developed countries, and promising to commit themselves to reduce their national greenhouse gas emissions.
} 
these barriers is not just important for a newly industrialized country like Taiwan, but also for the international climate regime. A number of articles discuss the approach of IA as a tool to mobilize climate policies (Hourcade et al., 2001; ICIS, 1999; IPCC, 1995; Moss et al., 2001). This approach is discussed in the following sections.

\subsection{Mechanism of $I A$}

IA generally involves an interdisciplinary process of structuring knowledge elements from various scientific disciplines in such a manner that all relevant aspects of a social problem are considered in their mutual coherence for the benefit of decision-making (ICIS, 1999). Accordingly, there are three significant elements in this approach: interdisciplinary integration, structuring of knowledge, and decision support. Under this framework, the scientific community needs to assess issues in an integrative manner combining social, economic, environmental, and institutional disciplines with analytical tools such as indicators, models, scenarios, and risk analysis. A dialogue between scientists and stakeholders, such as governmental agencies, businesses, NGOs, and citizens, is an important step for consensus building using the analytical tools to construct national climate protection strategies and action plans.

IA integrates economic, ecological, and social interests in such a manner as to improve the quality of political decision-making. Facing such complex issues as global change and sustainable development, the approach of traditional assessment fails to grasp the interactive relationships and feedbacks among the issues on one hand, and to develop a multipurpose decision support framework on the other. Therefore, environmental policy requires tools like IA to develop an integrated policy framework.

\subsection{Current operational conditions in Taiwan}

The practice of IA has emerged in Taiwan since some environment-related governmental agencies were reorganized and integrative projects have been introduced from the late 1990s. Current operations in this form are depicted in Fig. 8 and are discussed in subsequent sections.

\subsubsection{Development of analytical tools}

During the last decade, the National Science Council and EPA in Taiwan have commissioned numerous projects to develop IA-related analytical tools for political decision-making. A draft indicator system has been established which integrates social, economic, environmental, ecological, institutional, and urban issues. Tasks which have been achieved include calculation of the indicators, presentation of the core indica-

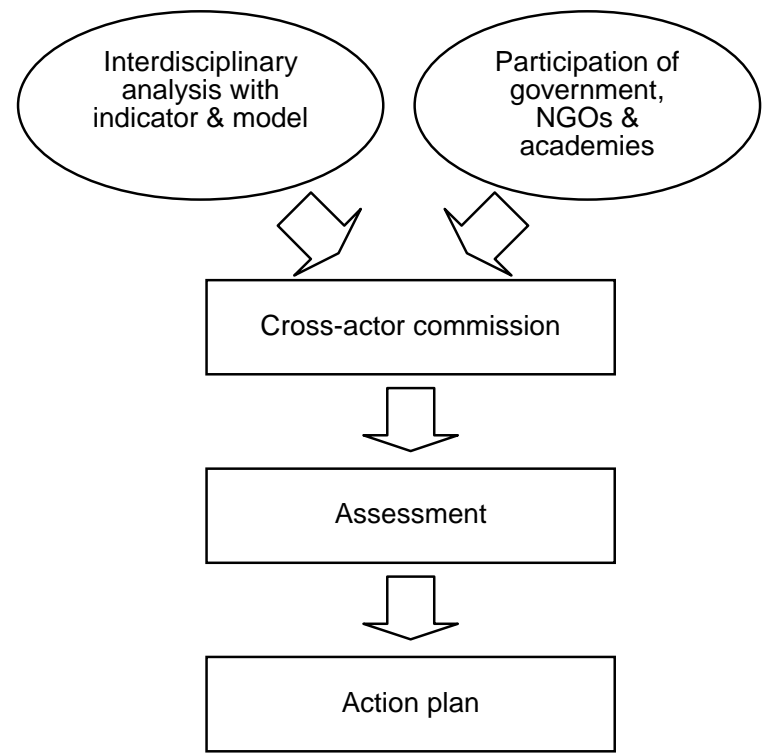

Fig. 8. Framework of integrative assessment in Taiwan.

tors, collection of information on weighting, and presentation of the indicators and suggestions for institutions responsible for generating data required for calculation of the indicators. In the second phase, the indicator system has the following missions.

- Policy application: using indicators for policy analysis and decision-making.

- Institutionalization: appointing institutions to be responsible for generating data required for calculation of indicators.

- Internalization: comparing the results of national indicators in a multilateral context.

- Localization: searching for suggested indicators based on the national indicator system for local use.

Moreover, a model has been built called "Threshold 21 for Taiwan" using the system dynamic software of VENSIM for a "what-if" investment policy analysis. However, the results of modeling have not been applied to practical decision-making as yet, possibly because investment policy alone fails to provide sufficient information and convictions for sustainable decisionmaking. A MARKAL-model has been developed and will be used to plan the development of future energy systems.

\subsubsection{Institutional participation}

The issue of climate change is strongly linked to energy and resource usage, economic policies, transportation, finance, and other sectors. In practice, the EPA is responsible for climate policies in Taiwan but has played little direct part in developing economic instruments, as in many countries (Helm, 2000). Integration of crossagency issues is a great challenge for effective climate 
policies. The Cabinet established a National Sustainable Development Council (NSDC) in 1997 for the purpose of coordinating and evaluating national sustainable development policies. After its reorganization in 2002, members of the Council are composed of government ministers, as well as representatives from NGOs and the academic community. Eight working groups have been established under the Commission and are involved in the following issues: sustainable vision, land resources, resources and industry, biodiversity, livelihood and production, international environmental protection, health risks, and education on sustainability. A representative from an NGO acts as a co-convener of each working group.

The participation of governmental agencies in climate policies in Taiwan often generates difficulties of crossissue and cross-agency integration. There are new government plans for organizational reform attempts to integrate agencies and their authorities for the purpose of improving administrative effectiveness in Taiwan. A new agency called the ERA will accordingly be established to integrate the tasks of the existing EPA, the Energy Commission of the Ministry of Economic Affairs, and other agencies responsible for such areas as water resources management.

\subsubsection{Implementation}

The NSDC plays a particularly important role in the integration of national sustainable development policies in Taiwan. A working group called "Atmospheric Protection and Energy" which was taken charge of by the EPA failed to integrate the EPA and other administrations in developing effective regulatory and economic instruments in the past. After its reorganization in 2002, eight workgroups under the Commission are obligated to list and propose political measures with timetables for the purpose of effective management and assessment, and to facilitate passing of legislation within a given time frame.

The difference that the reorganization made is that members of every working group come not just from governmental agencies, but also from NGOs and the academic community. It is expected that this combination will facilitate cross-issue and cross-agency integration on one hand, and accelerate political processes and administrative efficiency through supervision from NGOs and the academic community on the other.

\subsection{Challenges of IA for Taiwan's climate policy}

There are still challenges for the further development of IA in Taiwan which are detailed here.

\subsubsection{Strengthening analytical tools}

For mitigating global warming, what-if analyses with key indicators have proven to be useful tools for goal- oriented policies and action plans. Considering that indicator systems often fail to take into account interactions and feedback loops among various influential factors, the integration of models and indicators seems capable of overcoming this shortcoming and of producing valuable insights for sustainable decisionmaking.

\subsubsection{Applying analytical tools to decision-making}

The analytical tools developed so far have not yet been cogently used for drawing up effective climate policies in Taiwan. Long-term operation and publication of the indicator system are needed for decisionmaking and the raising of awareness. Application of the model will also be useful for target-oriented measures.

\subsubsection{Integrating stakeholders and information}

The NSDC have paved the way for better dialogue among various actors in Taiwan. The planned establishment of the ERA is also expected to address crossagency issues more effectively. The extent of coordination and integration among stakeholders in the future will profoundly influence the effectiveness of national climate policies. This integration holds not only for stakeholders, but also for the sustainable development database, in particular the database of the human dimension.

\section{Low-carbon strategies}

Provided that energy utilization remains inevitable in future socioeconomic systems, a more holistic and realistic approach is needed to address ways of reducing energy consumption of the socioeconomic system on the demand side, while shaping an energy structure with low environmental impacts on the supply side. These issues in Taiwan are addressed in the next sections, respectively.

\subsection{Transition of the economic structure}

Expansion of manufacturing industries in Taiwan brought about the high GDP growth rate, but also high growth rates of fossil fuel consumption and $\mathrm{CO}_{2}$ emissions since the 1970s. The share of the output value of high-polluting industries of the total domestic output value has continually increased to date. A transition of Taiwan's economic structure needs to occur from traditionally material- and energy-intensive petrochemical and steel industries to a service and information economy with energy-efficient technologies.

Moreover, Taiwan's economic activities have mostly accounted for processes of producing commodities so far. The domestic recycling rate of the total waste volume was only about $5.6 \%$ in 2000 . New legislation is 
needed to force businesses to integrate recycling into their treatment processes in order to reduce the resource and energy intensity of the entire economic system. The traditional development pattern of pursuing one-sided economic growth at the expense of environmental integrity neglects inter- and intra-generational equity. There has to be a new value paradigm of decisionmaking to balance economic, social, and environmental sustainability.

\subsection{Expanding the range of energy savings}

The argument that sustainable energy policies start from the point of consumption, not of supply, emphasizes end-use energy efficiency (Hill et al., 1995). This emphasis is justifiable, when examining the traditional falsehood prevailing in Taiwan's society: faced with public concern over a shortage of energy/electricity supply in the future, politicians must attempt to ensure the public and industry that there is a sufficient energy supply, without underscoring the significance of energy saving.

The data indicate that domestic energy consumption in Taiwan increased by 75\% from 1990 to 2000 (Fig. 9), and final energy demand is predicted to increase by $64 \%$ from 2000 to 2020. Although the increase in energy consumption has relatively slowed down, the planned energy savings rate of $28 \%$ from 1997 to 2020 appears to be insufficient in comparison with the high growth rate of future energy demand. There is still need to further cut the energy demand, particularly in industry, transport, and buildings. Regulatory measures recommended including tougher building codes requiring insulation and energy efficiency as well as changing to energyefficient light switches, etc. (Owen et al., 1998). An energy law is needed to impose the responsibility of limiting greenhouse gas emissions on the energy industry, and to ensure all necessary political instruments for energy savings. A law for energy audits is also

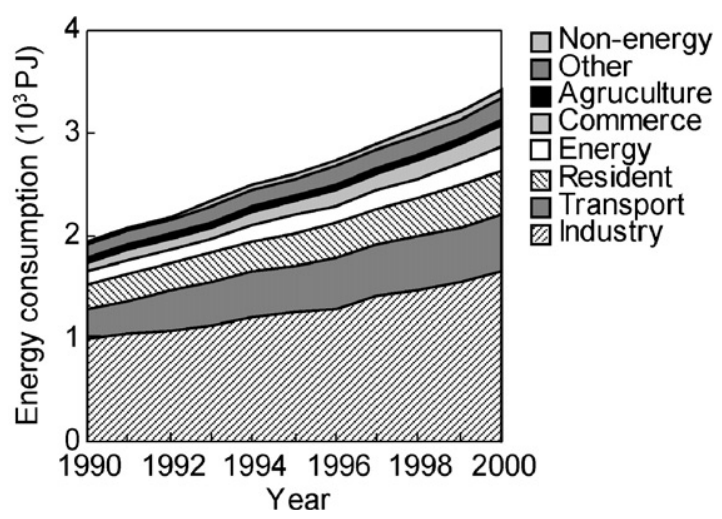

Fig. 9. Sectoral energy consumption 1990-2000 in Taiwan (source: EPAROC, 2002). needed to request reports about energy usage and improvement plans from energy-intensive branches.

The shortage of incentives is deemed a key barrier to implementing energy savings in Taiwan. Economic measures, such as tax exemptions and financial aid for investment in energy-saving technologies, appear to be of significance in removing this hurdle. Pearce argued that the resources that are most threatened are those without a market (Pearce, 1993). The transition toward an energy-efficient society needs to address issues of internalization the externalities. When market prices are less than social costs, businesses and consumers tend to demand more goods than is best for society (Goulder, 2000). Generally, market prices of energy and electricity in Taiwan do not include the external costs associated with damage to health and the environment. Fees for preventing air pollution levied with gas consumption since 1995 have not been based on internalization of external costs. The task of internalization will not only help reflect the real social costs of energy, but also develop a national green accounting and cost-benefit analysis for policies. As a whole, deploying these regulatory and economic measures would stimulate exploration of the enormous untapped potential for cutting national energy use.

\subsection{Gradually replacing fossil fuels and nuclear energy with renewable energy sources}

Sustained emphasis on fossil fuel-intensive technologies will dramatically increase global $\mathrm{CO}_{2}$ emissions, $\mathrm{CO}_{2}$ concentrations, and global mean temperature. The World Energy Council estimated that the "reserves" of fuel oil and natural gas may only be available until the middle of the 21 st century considering global energy consumption trends and technical conditions of future energy exploitation (Houghton, 1997). However, the IPCC-report pointed out that there remains abundant fossil fuel "resources" that will not limit carbon emissions during the 21 st century. The choice of an energy mix will determine whether greenhouse concentrations can be stabilized (IPCC, 2001b). In these contexts, a transition toward a low-carbon energy system is important for simultaneously covering energy demand and protecting climate systems in the future.

Exploration of renewable energy sources will play a particularly significant role in this context. Distributed generation can reduce grid losses, and stabilize the supply in areas remote from generation (ECDGE, 1998). This is particularly inspiring under the consideration that Taiwan's currently centralized generation system is subject to paralysis of the regional electricity supply due to grid damage during such common natural disasters as typhoons and earthquakes (Yue et al., 2001).

In order to respond to the development of global climate protection, Taiwan's Cabinet ratified the 
Development Program of Renewable Energy Sources in 2002. According to this Program, the share of renewable energy sources in total energy supply is projected to reach $3 \%$ for the year 2020 , and even to $6 \%$ with a more-active institutional promotion mechanism. The share of power generation capacity from renewable energy sources could be enhanced to $15 \%$ in the total power generation capacity. This indicates that the new administration has recognized the potential contribution of renewable energy sources, and desires to promote the application of these technologies.

Assessment of the potential of renewable energy sources in Taiwan indicates that fully exploring renewable energy sources could produce about $210 \mathrm{TWh}$ of electricity and $43 \mathrm{TWh}$ of thermal energy per year (Yue, 2002). Calculated with a $40 \%$ mean power-generating efficiency, the amount of primary energy which could be substituted is $2046 \mathrm{PJ}$ per year. This corresponds to $50 \%$ of the domestic primary energy consumption of $4088 \mathrm{PJ}$ in 2001. Based on the national prediction of energy demand for the year 2020 (ECROC, 2002), the proportion of primary energy which could be substituted by renewable energy would amount to $32.8 \%$ of the total primary energy demand of 6246 PJ. The electricity produced by renewable energy sources could cover $33.7 \%$ of the predicted domestic electricity demand of $624 \mathrm{TWh}$.

Accordingly, there is the potential for renewable energy sources to reduce $\mathrm{CO}_{2}$ emissions by 74 million tons per year in Taiwan. This corresponds to $33 \%$ of national $\mathrm{CO}_{2}$ emissions in 2000. Provided that the level of $\mathrm{CO}_{2}$ emissions for 2020 are maintained at the level of the year 2000, there is the potential for renewable energy sources to reduce $33 \%$ of yearly $\mathrm{CO}_{2}$ emissions by 2020 . This level of potential is about equal to the planned achieved $\mathrm{CO}_{2}$ reduction by the flexible mechanism, and is 19 million tons more than that by expanding nuclear energy.

Based on strategic planning of the EPA and ECROC for the purpose of reducing $\mathrm{CO}_{2}$ emissions in Taiwan, the 55 million tons of the planned achieved $\mathrm{CO}_{2}$ reduction by the expansion of nuclear energy could fully be substituted by exploring renewable energy sources. The 19 million tons of $\mathrm{CO}_{2}$ reduction from the flexible mechanism could also be substituted by renewable energy sources. The remaining 55 million tons of $\mathrm{CO}_{2}$ reduction from the flexible mechanism should either be substituted by an increased energy saving rate and strengthened transformation of the economic structure initially, or be covered by CDM.

Some technologies and practices appropriate for specific local conditions in Taiwan should be prioritized, including:

- off-shore wind farms making full use of geographic advantages of the island;
- recycling of methane produced by livestock breeding and landfills for power generation;

- wind power plants which are less land-intensive than solar thermal and photovoltaic power plants (Yue et al., 2001);

- roof- and facade-based solar energy systems; and

- full utilization of increasing agricultural fallow land for biomass planting.

\section{Implications for international climate policy}

The global carbon volume of historic emissions from burning both fossil fuels and fossil fuel reserves may well be enough to supply fossil fuel usage leading to atmospheric concentrations beyond the level of $1000 \mathrm{ppm}$ according to IPCC's estimate. Including unconventional reserves and resources, the carbon volume of fossil fuels may even double the above concentration (IPCC, 2001b). Moreover, stabilization of atmospheric $\mathrm{CO}_{2}$ concentrations at 450,650 , or $1000 \mathrm{ppm}$ would require global $\mathrm{CO}_{2}$ emissions to drop below 1990 levels within a few decades, in about a century, or in about two centuries, respectively (IPCC, 2001a). These data signal two important implications. First, the problem of global warming might not be resolved by a shortage of fossil fuels, but by restricting the use of fossil fuels due to environmental limitations. Second, the longer the time needed to reduce greenhouse gas emissions below a certain stabilized level, the higher atmospheric greenhouse gas concentrations will rise. Thus, global greenhouse gas reduction should occur as rapidly as possible in order to keep atmospheric greenhouse gas concentrations at less risky levels.

What do these imperatives imply for the international community, particularly for newly industrialized countries, such as Taiwan, and developing countries? The following discussion may shed light on the necessary interactions between these countries and the international community.

\subsection{Regulated emission limitations for newly industrialized countries}

It is possible that Taiwan and the United States will be the only political entities outside the restrictions of the Kyoto Protocol in the international community, although both entities have completely distinct backgrounds and characteristics leading to their exclusion. The United States withdrew from the Protocol because of its argued defects, while Taiwan is excluded from the membership of the United Nations as well as the United Nations Framework Convention on Climate Change (UNFCCC) due to diplomatic interference of the mainland Chinese government. Consequently, the United States can participate, but does not intend to do so. 
Taiwan intends to participate, but is not allowed to. Obviously, an effective global climate policy should aim at involving all countries in participation in emissions reductions with different mitigation levels and time schedules.

There are several reasons for giving Taiwan the legal status to participate in the Convention. The most important one is that Taiwan is a country with one of the greatest growth rates of greenhouse gas emissions worldwide. Taiwan's mitigation practices could serve a "showcase effect" for newly industrialized and developing countries. Moreover, the effective mitigation of Taiwan's emissions can only be achieved under the framework of the Convention with its rules and mechanisms. The absence of both Taiwan and the United States implies defects in the framework of the Convention. The challenge facing the global climate regime will be how to grant a country like Taiwan the legal status to participate in the Convention for common global mitigation.

The scenario analysis developed by the Global Scenario Group has concluded that a transition to sustainability appears to be technically feasible. A significant precondition is the emergence of sufficient political will for establishing a comprehensive set of policy reforms for a sustainability transition (National Research Council, 1999). In the context of the traditional pre-economic development logic in Taiwan, the presence of an internationally binding target for reducing greenhouse gas emissions appears to be particularly significant for invoking the domestic political will for climate protection.

The means of implementation plays a particularly significant role in Agenda 21 in order to realize desirable policies (UNCSD, 2000). Quantitative instruments such as direct regulation guarantee a particular impact on pollution. Setting a workable and binding emissions cap and the date by which the ceiling must be met through international negotiations appears to be the most important impetus to urge decision makers to move from declaration to real action. This target will help the entire society identify the needs and goals of climate policy which is deemed to be the first step for effective environmental management (Barrow, 1999). The agreement should be negotiated and achieved as rapidly as possible in order to encourage Taiwan, together with other newly industrialized countries, to take earlier actions to mitigate greenhouse gas emissions.

The necessity of a binding target for emissions reductions holds not just for Taiwan, but also for other newly industrialized countries. These countries generally show expanding economic activities. As a result, greenhouse gas emissions of these countries have outstripped those of some developed countries. Imposing emission caps on these countries seems to be the most effective means at the international level of curbing the trends of burgeoning emissions.

In addition to ethical motivations, there are also economic reasons for emissions limits for newly industrialized countries. A cost-effective abatement will require that abatement be undertaken in non-Annex I countries. Emission caps would therefore need to be negotiated for developing countries (Barrett, 2000). The creation of incentives by cost-effective abatement would provide better conditions to deter free-riding and noncompliance in future global climate policies. The withdrawal of the Bush administration from the Kyoto Protocol illustrates the necessity for developing countries to participate in emissions limitations in the postKyoto climate policy.

\subsection{Carbon taxes}

Discussions on introducing carbon taxes are not new but represent an ongoing issue in climate policy. Part of the impetus for the taxation of carbon emissions comes from the recognition of the limitation of environmental policies pursued solely through conventional regulatory instruments (Smith, 2000). The restricted usage of this instrument at the national level has so far weakened its effect to a great extent.

The advantages of carbon taxes are:

- providing polluters with encouragement to make reductions in pollution beyond what regulations require;

- spreading the burden of adjustment across all energy users;

- providing relatively low operating costs; and

- providing more-accurate emission figures than do emission inspections.

In addition to the regulatory approach as emission caps for countries, economic approaches can complement the effectiveness of emissions limitations. To achieve a more-applicable implementation, carbon taxes can be pegged differently contingent on the level of economic development of various countries. Alternatively, the tax structure could also impose higher tax rates on countries with higher per-capita emissions.

Carbon taxes can be most equally and effectively implemented at the international level. To this end, the UNFCCC needs to play a more-active role in arranging this economic instrument in order to enhance the effectiveness and credibility of implementing these instruments. Under this framework, the EPA may have greater justification to tax domestic carbon emissions in Taiwan. Before a carbon tax is realized at the international level, Taiwan may consider the taxation of domestic carbon emissions in order to establish a self-funding mechanism for environmentally benign 
technologies such as renewable energies. The so-called "feebate" mechanism taxes products which create more pollution during their production (Woodward et al., 2000). Tax revenues may be used to support buyers of clean products.

\subsection{Clean development mechanisms}

As described above, only members of Taiwan's private sector that have branches in signatory countries of the Convention have the possibility of participating in CDM projects, since Taiwan is excluded from signing the Kyoto Protocol. The credits of emissions reductions from these projects will not belong to Taiwan. If Taiwan can not gain the credits of emissions reductions, there is even less incentive for the government and business to participate in CDM projects. It is therefore conceivable that a precondition of Taiwan's active participation in CDM may be either legal status of membership to the Convention, or a gain of credits for emissions reductions.

The arrangement of the CDM still needs to be improved. The Kyoto Protocol Adaptation Fund dictates that $2 \%$ of the proceeds from CDM trades be used to assist developing country parties that are particularly vulnerable to the adverse effects of climate change to meet the costs of adaptation. However, if the $\mathrm{CDM}$ is to be promoted, it is more rational to subsidize the trade rather than to tax it. Moreover, it is desirable that introducing the CDM be complementary to other instruments, such as direct technology transfers and/or investment, in order to enrich the contents and to enhance the efficiency of the CDM.

\subsection{Institutional and technological transfers}

Paragraph (c), article 10 of the Kyoto Protocol requires that all parties cooperate in the promotion of effective modalities for the development, application, and diffusion of environmentally sound technologies and practices pertinent to climate change including the formulation of policies and programs for the effective transfer of environmentally sound technologies. The priority of the cooperation may focus on the following practices:

- the development of analytical tools like modeling and indicator systems;

- participatory tools; and

- the development, application, and distribution of renewable energy sources.

The cooperation between Taiwan and the international community has mostly focused on technological rather than institutional transfers in the past. Such a bias has led to the lack of effective policies and measures to apply and distribute new technologies in Taiwan. The development of wind power is one such example. The transfer of political concepts and instruments should gain at least as much importance as climate-benign technologies in future cooperation between Taiwan and the international community.

\section{Conclusions}

Efforts made by the United Nations Framework Convention on Climate Change (UNFCCC) are currently focused on establishing the implementation mechanism of the Kyoto Protocol in order to mitigate greenhouse gas emissions of industrialized countries, for these countries are the main emitters of global greenhouse gases to date. Although the withdrawal of the Bush administration from the Kyoto Protocol demonstrates a lack of participation of a major polluter of the world against global warming, it indeed indicates the necessity for newly industrialized and developing countries to participate in effective emissions limitations.

The fact that more-rapid action would show more promise in stabilizing the global climate system implies that early involvement of newly industrialized and developing countries may decrease human risks associated with rapid climate changes. However, both the request for future participation of newly industrialized countries in mitigating greenhouse gas emissions, and the search for effective cooperation of these countries with the international community have to be based on a sound understanding of the development trends of greenhouse gas emissions, and the conditions of climate policies in those countries.

This study analyzes the dilemmas and opportunities of Taiwan's climate policies against burgeoning greenhouse gas emissions and reaches the following conclusions.

- Greenhouse gas emissions in Taiwan rapidly increased by $69 \%$ from 1990 to 2000 . The per-capita $\mathrm{CO}_{2}$ emissions from fossil fuel combustion increased by $76 \%$, and have already exceeded those of some OECD countries such as Japan and the UK.

- The share of emissions from the energy sector rose from $76.7 \%$ to $85.8 \%$ during this period. Energyrelated $\mathrm{CO}_{2}$ emissions are the most significant issue in national climate policy.

- Full exploitation of renewable energy sources in Taiwan could reduce $33 \%$ of the planned national $\mathrm{CO}_{2}$ emissions by 2020 . This could fully substitute for the $\mathrm{CO}_{2}$ reduction by the planned expansion of nuclear energy, and partly substitute for the $\mathrm{CO}_{2}$ reduction which is expected to be achieved by the flexible mechanism. 
- The approach of IA provides a framework by which to apply analytical tools for policy analysis and to fill in gaps among various stakeholders that can be used to effectively address the lack of political will and of an implementation mechanism, which are the key barriers to a climate policy in Taiwan.

- Newly industrialized countries like Taiwan generally show intentions of expanding economic activities which will cause burgeoning greenhouse gas emissions. Imposing emission caps on these countries seems to be the most effective means of curbing rising emissions within a reasonable time frame. Based on internationally agreed reduction targets, governmental agencies could have legitimate justifications to promote more-active climate policies with a variety of policy instruments.

- A carbon tax, as a cost-effective economic instrument of climate policy to achieve emissions reductions, ideally needs to be adopted at the international level in a manner that equitably reflects different levels of emissions and economic development between countries. Under this framework, multinational participation is more realizable.

- Restrictions set by the CDM mechanism restrain Taiwan from participating in this program. Assurances of the gain of credits for emissions reductions may be a precondition for Taiwan's active participation.

Stabilizing the global climate system is a common responsibility of all nations, groups, and individuals worldwide. Greenhouse gas emissions in some newly industrialized countries like Taiwan have already reached levels high enough that these nations should be urged to consider bearing part of the obligation of mitigating emissions. This study can shed light on the predicaments and opportunities of the climate policy in Taiwan as an illustrative example so that international climate policy can be informed about current development trends, and be able to make timely considerations to address the challenges of mitigating greenhouse gas emissions in newly industrialized and developing countries. Our common future relies on our common action, and that action taking place in a timely manner.

\section{References}

Barrett, S., 2000. Political economy of the Kyoto Protocol. In: Helm, D. (Ed.), Environmental Policy. Oxford University Press, Oxford.

Barrow, C.J., 1999. Environmental Management: Principles and Practice. Routledge, London.

Chen, S.W., 2000. Strategies and perspective for Taiwan's response to the United Nations Framework Convention on Climate Change. Paper of the Environmental Protection Administration of the Republic of China, Taipei, Taiwan.
DGBAS (Directorate-General of Budget, Accounting and Statistics) of the ROC (Republic of China), 2002. Social indicator statistics of the Republic of China. Available at: http://www.dgbas.gov.tw/ dgbas03/bs2/90chy/catalog.htm.

ECDGE (European Commission's Directorate General for Energy), 1998. Wind Energy-The Facts. AGORES (A Global Overview of Renewable Energy Sources), website: http://www.agores.org/ Publications/Wind_Energy.htm.

ECROC (Energy Commission of the Republic of China), 1998. White paper of energy policy of the Republic of China, Taipei, Taiwan.

ECROC (Energy Commission of the Republic of China), 2002. The statistics of energy demand and supply in Taiwan. ECROC web-site: http://www.moeaec.gov.tw/07/ecw07.asp?href=01/ecw0701. asp\&kind $=\mathrm{T} 0001$.

EPAROC (Environmental Protection Administration of the Republic of China, 2002. Information Website of the UNFCCC. ITRI Website: http://sd.erl.itri.org.tw/fccc/.

Goulder, L.H., 2000 . Steps from environmental science to effective policy. In: Ernst, W.G. (Ed.), Earth Systems. Cambridge University Press, Cambridge, pp. 425-433.

Helm, D., 2000 . Objectives, instruments, and institutions. In: Helm, D. (Ed.), Environmental Policy. Oxford University Press, Oxford.

Hill, R., O'Keefe, P., Snape, C., 1995 . Energy planning. In: Kirkby, J., O'Keefe, P., Timberlake, L. (Eds.), The Earthscan Reader in Sustainable Development. Earthscan Publications, London, pp. $78-98$.

Houghton, J., 1997. Globale Erwärmung. Springer, Berlin.

Hourcade, J.-C., Ha-Duong, M., Grübler, A., Tol, R.S.J., 2001. INASUD project findings on integrated assessment of climate policies. Integrated Assessment 2, 31-35.

ICIS (International Centre for Integrative Studies), 1999. Integrated assessment: a bird's-eye view. ICIS Website: http://www.icis.unimaas.nl/downs/Summerschoolintro.doc.

IEA (International Energy Agency), 1999. Key world energy statistics. IEA Website: http://www.iea.org/stats/files/keystats/key99.pdf.

IEA (International Energy Agency), 2001. Key world energy statistics. IEA Website: http://www.iea.org/statist/key2001/keyworld2001.pdf.

IEA (International Energy Agency), 2002. Key world energy statistics. IEA Website: http://www.iea.org/statist/keyworld2002/key2002/ keystats.htm.

IPCC, 1995. Climate change 1995: IPCC second assessment report. IPCC Website: http://www.ipcc.ch.

IPCC, 2001a. Climate change 2001: the scientific basis. Summary for policymakers. A Report of Working Group I of the Intergovernmental Panel on Climate Change. IPCC Website: http:// www.ipcc.ch.

IPCC, 2001b. Climate change 2001: mitigation. Summary for policymakers. A Report of Working Group III of the Intergovernmental Panel on Climate Change. IPCC Website: http://www.ipcc.ch.

ITRI (Industrial Technology Research Institute), 2001. Greenhouse gas emissions in Taiwan. ITRI Website: http://www.itri.org.tw/.

Moss, S., Pahl-Wostl, C., Downing, T., 2001. Agent-based integrated assessment modelling: the example of climate change. Integrated Assessment 2, 17-30.

National Research Council, 1999. Our Common Journey. National Academy Press, Washington, DC.

Owen, O.S., Chiras, D.D., Reganold, J.P., 1998. Natural Resource Conservation.. Prentice-Hall, Upper Saddle River, New Jersey.

Pearce, D., 1993. Measuring Sustainable Development. Earthscan Publications, London.

Smith, S., 2000 . Environmental and public finance aspects of the taxation of energy. In: Helm, D. (Ed.), Environmental Policy. Oxford University Press, Oxford.

UN (United Nations), 2002. Population database. UN Website: http:// esa.un.org/unpp/. 
UNCSD (UN Commission on Sustainable Development), 2000. Agenda 21. UNCSD Website: http://www.un.org/esa/sustdev/ agenda2 1 text.htm.

UNFCCC (United Nations Framework Convention on Climate Change), 1997. Kyoto Protocol to the United Nations Framework Convention on Climate Change. UNFCCC Website: http:// ghg.unfecc.int/.

UNFCCC (United Nations Framework Convention on Climate Change), 2002. Greenhouse gas inventory database. UNFCCC Website: http://ghg.unfccc.int/.

Weyant, J., Yanigisawa, Y., 1998 . Energy and industry. In: Rayner, S., Malone, E.L. (Eds.), Human Choice and Climate Change. Vol. 2: Resources and Technology. Battelle Press, Columbus, OH, pp. 203-289.
Woodward, J., Place, C., Arbeit, K., 2000 . Energy resources and the environment. In: Ernst, W.G. (Ed.), Earth Systems. Cambridge University Press, Cambridge.

Young, R.-T., 1999. Evaluation of future $\mathrm{CO}_{2}$ emissions and response energy measures for Taiwan. Energy Quarterly 29 (14), 17-34.

Yue, C.-D., 2002. Assessment of potential of renewable energy sources in national climate policies in Taiwan. Conference Paper of The Workshop for Environmental and Resource Economics, Management and System Analysis in 2002, Taipei Institute of Natural Resource Management, National Taipei University, Taipei.

Yue, C.-D., Liu, C.-M., Liou, E.M.L., 2001. A transition toward a sustainable energy future: feasibility assessment and development strategies of wind power in Taiwan. Energy Policy 29, 951-963. 